\title{
WORKING RULES
}

\author{
Prague, Czech Republic, 25 August 2006
}

\section{INTRODUCTION AND RATIONALE}

The Statutes of the International Astronomical Union (IAU) define the goals and organizational structure of the Union, while the Bye-Laws specify the main tasks of the various bodies of the Union in implementing the provisions of the Statutes. The Working Rules are designed to assist the membership and governing bodies of the Union in carrying out these tasks in an appropriate and effective manner. Each of the sections below is preceded by an introduction outlining the goals to be accomplished by the procedures specified in the succeeding paragraphs. The Executive Committee updates the Working Rules as necessary to reflect current procedures and to optimize the services of the IAU to its membership.

\section{NON-DISCRIMINATION}

The International Astronomical Union follows the regulations of (ICSU): The International Council for Science and concurs with the actions undertaken by their Standing Committee on Freedom in the Conduct of Science on non-discrimination and universality of science ( $c f . \S 21$ below).

\section{NATIONAL MEMBERSHIP}

The aim of the rules for applications for National Membership is to ensure that the proposed National Member adequately represents an astronomical community not already represented by another Member, and that such membership will be of maximum benefit for the community concerned ( $c f$. Statutes $\S$ IV).

1. Applications for National Membership should therefore clearly describe the following essential conditions:

1.a. the precise definition of the astronomical community to be represented by the proposed Member;

1.b. the present state and expected development of that astronomical community;

1.c. the manner in which the proposed National Member represents this community;

1.d. whether the application is for membership on a permanent or interim basis; and

1.e. the category in which the prospective National Member wishes to be classified (cf. Bye-Laws $\S 25)$.

2. Applications for National Membership shall be submitted to the General Secretary, who will forward them to the Executive Committee for review as provided in the Statutes. 


\section{INDIVIDUAL MEMBERSHIP}

Professional scientists whose research is directly relevant to some branch of astronomy are eligible for election as Individual Members of the Union ( $c f$. Statutes $\S \mathrm{V}$ ). Individual Members are, normally, admitted by the Executive Committee on the proposal of a National Member. However, Presidents of Divisions may also propose individuals for membership in cases when the normal procedure is not applicable or practicable ( $c f$. Bye-Laws $\S 4$ ). The present rules are intended to ensure that all applications for membership are processed on a uniform basis, and that all members are fully integrated in and contributing to the activities of the Union. Thus, the General Assembly appoints a Nominating Committee with a small number of members ( $c f$. Statutes $\S 13 . f$.) and it, or a Sub-Committee which it appoints, may remain in office until the next General Assembly to allow more time for its work.

3. The term "Professional Scientist" shall normally designate a person with a doctoral degree (Ph.D.) or equivalent experience in astronomy or a related science, and whose professional activities have a substantial component of work related to astronomy.

4. National Members and Division Presidents may propose Individual Members who fall outside the category of professional scientist but who have made major contributions to the science of astronomy, e.g., through education or research related to astronomy. Such proposals should be accompanied by a detailed motivation for what should be seen as exceptions to the rule.

5. Eight months before an ordinary General Assembly, National Members and Presidents of Divisions will be invited to propose new Individual Members; these proposals should reach the General Secretary no later than five months before the General Assembly. Late proposals will normally not be taken into consideration. Proposals from Presidents of Divisions will be submitted by the IAU 3 months before the General Assembly to the relevant National Members, if any, who may add the person(s) in question to their own list of proposals.

6. National Members are urged to propose the deletion of Individual Members who are no longer active in astronomy. Such proposals should be done in consultation with the member concerned and submitted to the General Secretary at the same time as proposals for new Individual Members. National Members shall also promptly inform in writing the General Secretary of the death of any Individual Member represented by them.

7. Proposals for membership shall include the full name, date of birth, and nationality of the candidate, postal and electronic addresses, the University, year, and subject of the M.Sc./Ph.D. or equivalent degree, current affiliation and occupation, the proposing National Member or Division, the Division(s) and/or Commission(s) which the candidate wishes to join, and any further detail that might be relevant.

8. The General Secretary shall submit all proposals for Individual Membership to the Nominating Committee for review, consolidated into two lists:

8.a. one containing all proposals by National Members; and

8.b. one containing all proposals by Presidents of Divisions, in accordance with ByeLaw $\S 4$.

9. The Nominating Committee shall examine all proposals for individual membership and advise the Executive Committee on their approval or rejection.

10. In exceptional cases, the Executive Committee may, on the proposal of a Division, admit an Individual Member between General Assemblies. Such proposals shall be prepared as described above $(c f ., \S 2$ and submitted with a justification of the request to 
bypass the normal procedure. The Executive Committee shall consult the Nominating Committee or relevant National Member, if any, if a standing NC of manageable size has not been appointed, before approving such exceptions to the normal procedure.

11. The General Secretary shall maintain updated lists of all National and Individual Members, and shall make these available to the membership in electronic form. The procedures for dissemination of these lists shall be set by the General Secretary in such a way that the membership directory be properly protected against unintended or inappropriate use.

\section{RESOLUTIONS OF THE UNION}

Traditionally, the decisions and recommendations of the Union on scientific and organizational matters of general and significant importance are expressed in the Resolutions of the General Assembly. In order for such Resolutions to carry appropriate weight in the international community, they should address astronomical matters of significant impact on the international society, or matters of international policy of significant importance for the international astronomical community as a whole. Resolutions should be adopted by the General Assembly only after thorough preparation by the relevant bodies of the Union. The proposed resolution text should be essentially complete before the beginning of the General Assembly, to allow Individual and National Members time to study them before the vote by the General Assembly. The following procedures have been designed to accomplish this:

12. Proposals for Resolutions to be adopted by the General Assembly may be submitted by a National Member, by the Executive Committee, a Division, a Commission or a Working Group. They should address specific issues of the nature described above, define the objectives to be achieved, and describe the action(s) to be taken by the Officers, Executive Committee, or Divisions to achieve these objectives.

13. Resolutions proposed for vote by the General Assembly fall in two categories:

13.a. Resolutions with implications for the budget of the Union; or

13.b. Resolutions without financial implications.

Proposals for Resolutions should be submitted on standard forms appropriate for each type, which are available from the IAU Secretariat. They may be submitted in either English or French and will be discussed and voted upon in the original language. Upon submission each proposed Resolution is posted on the Union web site. When the approved Resolutions are published, a translation to the other language will be provided.

14. Resolutions of type A must be submitted to the General Secretary at least nine months before the General Assembly in order to be taken into account in the budget for the impending triennium. Resolutions of type B must be submitted to the General Secretary three months before the beginning of the General Assembly. The Executive Committee may decide to accept late proposals in exceptional circumstances.

15. Before being submitted to the vote of the General Assembly, proposed Resolutions will be examined by the Executive Committee, Division Presidents, and by a Resolutions Committee, which is nominated by the Executive Committee. The Resolutions Committee consists of at least three members of the Union, one of whom should be a member of the Executive Committee, and one of whom should be a continuing member from the previous triennium. It is appointed by the General Assembly during its final session and remains in office until the end of the following General Assembly. 
16. The Resolutions Committee will examine the content, wording, and implications of all proposed Resolutions promptly after their submission. In particular, it will address the following points:

i. suitability of the subject for an IAU Resolution;

ii. correct and unambiguous wording;

iii. consistency with previous IAU Resolutions.

The Resolutions Committee may refer a Resolution back to the proposers for revision or withdrawal if it perceives significant problems with the text, but can neither withdraw nor modify its substance on its own initiative. The Resolutions Committee advises the Executive Committee whether the subject of a proposed Resolution is primarily a matter of policy or primarily scientific. The Resolutions Committee will also notify the Executive Committee of any perceived problems with the substance of a proposed Resolution.

17. Proposed Resolutions shall be published in the General Assembly Newspaper before the final session.

18. The Executive Committee will examine the substance and implications of all proposed Resolutions. The Resolutions Committee presents the proposals during the second session of the General Assembly with its own recommendations, and those of the Executive Committee, if any, for their approval or rejection. A representative of the body proposing the Resolution is given the opportunity to defend the Resolution in front of the General Assembly, after which a general discussion takes place before the vote.

\section{EXTERNAL RELATIONS}

Contacts with other international scientific organizations, national and international public bodies, the media, and the public are increasing in extent and importance. In order to maintain coherent overall policies in matters of international significance, clear delegation of authority is required. Part of this is accomplished by having the Union's representatives in other scientific organization appointed by the Executive Committee (cf. Bye-Laws $§ 15$ ). Supplementary rules are given in the following.

19. Representatives of the Union in other scientific organizations are appointed by the Executive Committee upon consultation with the Division(s) in the field(s) concerned.

20. In other international organizations, e.g., in the United Nations Organization, the Union is normally represented by the General Secretary or Assistant General Secretary, as decided by the Executive Committee.

21. The Union strongly supports the policies of ICSU: The International Council for Science, as regards the freedom and universality of science. Participants in IAU sponsored activities who feel that they may have been subjected to discrimination are urged, first, to seek clarification of the origin of the incident, which may have been due to misunderstandings or to the cultural differences encountered in an international environment. Should these attempts not prove successful, contact should be made with the General Secretary who will take steps to resolve the issue.

22. Public statements that are attributed to the Union as a whole can be made only by the President, the General Secretary, or the Executive Committee. The General Secretary may, in consultation with the relevant Division, appoint Individual Members of the Union with special expertise in questions that attract the attention of media and the general public as IAU spokespersons on specific matters. 


\section{FINANCIAL MATTERS}

The great majority of the Union's financial resources are provided by the National Members, as laid out in the Statutes $\S$ XII and Bye-Laws $\S$ VII. The purpose of the procedures described below is twofold: (i) to provide the best possible advice and guidance to the General Secretary and Executive Committee in planning and managing the Unions financial affairs, and (ii) to provide National Members with a mechanism for continuing input to and oversight over these affairs between and in preparation for the General Assemblies. The procedures adopted to accomplish this are as follows:

23. At the end of each of its final sessions the General Assembly, at the proposal of the Finance Committee, appoints a Finance Sub-Committee of 5-6 members, including a Chair. The Finance Sub-Committee remains in office until the end of the next General Assembly ( $c f$. Statutes $\S 13 . d$.) and cooperates with the National Members, Finance Committee, Executive Committee and General Secretary in the following manner:

23.a. After the end of each year the General Secretary provides the Finance SubCommittee with the auditor's report and summary reports covering the financial performance of the Union as compared to the approved budget, together with an analysis of any significant departures, and information on any Executive Committee approvals for budget changes. Upon receipt of the above reports from the General Secretary, the Finance Sub-Committee examines the accounts of the Union in the light of the corresponding budget and any relevant later decisions by the Executive Committee. It reports its findings and recommendations to the Executive Committee at its next meeting. The Finance Sub-Committee may at any time, at the request of the Executive Committee or the General Secretary, or on its own initiative, advise the General Secretary and/or the Executive Committee on any aspect of the Union's financial affairs.

23.b. Early in the year preceding that of a General Assembly, the General Secretary shall submit a preliminary draft of the budget for the next triennium to the Finance SubCommittee for review. The draft budget, updated as appropriate following the comments and advice of the Finance Sub-Committee, is submitted to the Executive Committee for approval at the EC meeting in the year preceding that of a General Assembly, together with the report of the Finance Sub-Committee. The final budget proposal as approved by the Executive Committee is subsequently submitted to the National Members with a statement of the views of the Finance Sub-Committee on the proposal.

23.c. Before the first session of a General Assembly, the Finance Sub-Committee shall submit a report to the Executive Committee and the Finance Committee on its findings and recommendations concerning the development of the Union's finances over the preceding triennium. The Finance Sub-Committee shall also prepare a slate of candidates for the composition of the Finance Sub-Committee in the next triennium, preferably providing a balance between new and continuing members.

23.d. The report of the Finance Sub-Committee, together with the audited detailed accounts and the earlier comments on the proposed budget for the next triennium, will form a suitable basis for the discussions of the Finance Committee leading to its recommendations to the General Assembly concerning the approval of the accounts for the previous triennium and the budget for the next triennium, as well as the new Finance Sub-Committee to serve during that period.

24. The General Secretary is responsible for managing the Union's financial affairs according to the approved budget ( $c f$. Bye-Laws $\S 28$ ). 
24.a. In response to changing circumstances, the Executive Committee may approve such specific changes to the annual budgets as are consistent with the intentions of the General Assembly when the budget was approved.

24.b. Unless authorized by the Executive Committee, the General Secretary shall not approve expenses exceeding the approved budget by more than $10 \%$ of any corresponding major budget line or $2 \%$ of the total budget in a given year, whichever is larger. This restriction does not apply in cases when external funding has been provided for a specific purpose, e.g. travel grants to a General Assembly.

24.c. Unless specifically identified in the approved budget, contractual commitments in excess of 50,000 CHF or with performance terms in excess of 3 years require the additional approval of the Union President.

25. The National Representatives, in approving the accounts for the preceding triennium, discharge the General Secretary and the Executive Committee of liability for the period in question.

\section{RULES OF PROCEDURE FOR THE EXECUTIVE COMMITTEE}

The Executive Committee must respond quickly to events and thus it needs to be able to have discussions and take decisions on a relatively short timescale and without meeting in person. The following rules, as required by Bye-Law 14, are designed to facilitate EC action in a flexible manner, while giving such decisions the same legal status as those taken at actual physical meetings.

26. The Executive Committee should meet in person at least once per year. In years of a General Assembly it should meet in conjunction with and at the venue of the General Assembly. In other years, the Executive Committee decides on the date and venue of its regular meeting. The meetings of the Executive Committee are chaired by the President or, if the President is unavailable, by the President Elect or by one of the Vice-Presidents chosen by the Executive Committee to serve in this capacity.

27. The date and venue of the next regular meeting of the Executive Committee shall be communicated at least six months in advance to all its members and the Advisors, and to all Presidents of Divisions. Any of these persons may then propose items for inclusion in the Draft Agenda of the meeting before the date posted on the IAU Deadlines page.

28. Outgoing and incoming Presidents of Divisions are invited to attend all non-confidential sessions of the outgoing and incoming Executive Committee, respectively, in the years of a General Assembly. The President will invite Presidents of Divisions to attend the meetings of the Executive Committee in the years preceding a General Assembly. Division Presidents attend these sessions with speaking right, but do not participate in any voting.

29. The Executive Committee may take official decisions if at least half of its members participate in the discussion and vote on an issue. Decisions are taken by a simple majority of the votes cast. In case of an equal division of votes, the Chair's vote decides the issue. Members who are unable to attend may, by written or electronic correspondence with the President before the meeting, authorize another member to vote on her/his behalf or submit valid votes on specific issues.

30. If events arise that require action from the Executive Committee between its regular meetings, the Committee may meet by teleconference or by such electronic or other means of correspondence as it may decide. In such cases, the Officers shall submit a clear 
description of the issue at hand, with a deadline for reactions. If the Officers propose a specific decision on the issue, the decision shall be considered as approved unless a majority of members vote against it by the specified deadline. In case of a delay in communication, or if the available information is considered insufficient for a decision, the deadline shall be extended or the decision deferred until a later meeting at the request of at least two members of the Executive Committee.

31. The Officers of the IAU should, as a rule, meet once a year at the IAU Secretariat in order to discuss all matters of importance to the Union. The other members of the Executive Committee and the Division Presidents shall be invited to submit items for discussion at the Officers' Meetings and shall receive brief minutes of these Meetings.

32. Should any member of the Executive Committee have a conflict of interest on a matter before the Executive Committee that might compromise their ability to act in the best interests of the Union, they shall declare their conflict of interest. The remaining members of the Executive Committee determine the appropriate level of participation in such issues for members with a potential conflict of interest.

\section{SCIENTIFIC MEETINGS AND PUBLICATIONS}

Meetings and their proceedings remain a major part of the activities of the Union. The purpose of scientific meetings is to provide a forum for the development and dissemination of new ideas, and the proceedings are a written record of what transpired.

33. The General Secretary shall publish in the Transactions and on the IAU web site rules for scientific meetings organized or sponsored by the Union.

34. The proceedings of the General Assemblies and other scientific meetings organized or sponsored by the Union shall, as a rule, be published. To ensure prompt publication of Proceedings of IAU Symposia and Colloquia, the Assistant General Secretary is authorized to oversee the production of the material for the Proceedings. The Union shall publish an Information Bulletin at regular intervals to keep Members informed of current and future events in the Union. The Union shall also publish a more informal, periodic Newsletter which it distributes electronically to its members. The Executive Committee decides on the scope, format, and production policies for such publications, with due regard to the need for prompt publication of new scientific results and to the financial implications for the Union. At the present time, publications are in printed and in electronic form.

35. Divisions, Commissions, and Working Groups shall, with the approval of the Executive Committee, be encouraged to issue Newsletters or similar publications addressing issues within the scope of their activity.

\section{TERMS OF REFERENCE FOR DIVISIONS}

The Divisions are the scientific backbone of the IAU. They have a main responsibility for monitoring the scientific and international development of astronomy within their subject areas, and for ensuring that the IAU will address the most significant issues of the time with maximum foresight, enterprising spirit, and scientific judgment. To fulfill this role IAU Divisions should maintain a balance between innovation and continuity. The following standard Terms of Reference have been drafted to facilitate that process, within the rules laid down in the Statutes $\S \mathrm{X}$ and the Bye-Laws $\S \mathrm{V}$. 
36. As specified in Bye-Law 18, the scientific affairs of the Division are conducted by an Organizing Committee of up to 12 members of the Division, headed by the Division President, Vice-President, and Secretary. Thus, all significant decisions of the Division require the approval of the Organizing Committee, and the President and Vice-President are responsible for organizing the work of the Committee so that its members are consulted in a timely manner. Contact information for the members of the Organizing Committee shall be maintained at the Division web site.

37. Individual Members of the Union are admitted to membership in a Division by its Organizing Committee (cf. Bye-Laws 18). Individual Members active within the field of activity of the Division and interested in contributing to its development should contact the Division Secretary, who will consult the Organizing Committee on the admission of the candidates.

37.a. The Division Secretary shall maintain a list of Division members for ready consultation by the community, including their Commission memberships if any. Updates to the list shall be provided to the IAU Secretariat on a running basis.

37.b. Members may resign from a Division by so informing the Division Secretary.

38. The effectiveness of the Division relies strongly on the scientific stature and dedication of its President and Vice-President to the mission of the Division. The Executive Committee, in proposing new Division Presidents and Vice-Presidents for election by the General Assembly, will rely heavily on the recommendations of the Organizing Committee of the Division. In order to prepare a strong slate of candidates for these positions, and for the succession on the Organizing Committee itself, the following procedures apply:

38.a. Candidates are proposed and selected from the membership of the Division on the basis of their qualifications, experience, and stature in the fields covered by the Division. In addition, the Organizing Committees should have proper gender balance and broad geographical representation.

38.b. At least six months before a General Assembly, the Organizing Committee submits to the membership of the Division a list of candidates for President, Vice-President (for which there should be at least two persons willing to serve), Secretary, and the Organizing Committee for the next triennium. The Organizing Committee requests nominations from the membership in preparing this list, and accepts additional nominations within a month after its submission to the membership. The Vice-President is normally nominated to succeed the President. The outgoing President participates in the deliberations of the new Organizing Committee in an advisory capacity.

38.c. If more names are proposed than there are positions to be filled on the new Organizing Committee, the outgoing Organizing Committee devises the procedure by which the requisite number of candidates is elected by the membership. The resulting list is communicated to the General Secretary at least two months before the General Assembly. The General Secretary may allow any outstanding issues to be resolved at the business meeting of the Division during the General Assembly.

38.d. A member of the Organizing Committee normally serves a maximum of two terms, unless elected Vice-President of the Division in her/his second term. Presidents may serve for only one term.

38.e. The Organizing Committee decides on the procedures for designating the Division Secretary, who maintains the web site, records of the business and membership of the Division, and other rules for conducting its business by physical meetings or by correspondence. 
39. A key responsibility of the Organizing Committee is to maintain an internal organization of Commissions and Working Groups in the Division which is conducive to the fulfillment of its mission. The Organizing Committee shall take the following steps to accomplish this task in a timely and effective manner:

39.a. Within the first year after a General Assembly - with the business meeting of the Commission at the General Assembly itself as a natural starting point - the Organizing Committee shall discuss with its Commissions, and within the Organizing Committee itself, if changes in its Commission and Working Group structure may enable it to accomplish its mission better in the future. As a rule, Working Groups should be created (following the rules in Bye-Law $\S 21$ and Bye-Law $\S 23$ ) for new activities that are either of a known, finite duration or are exploratory in nature. If experience, possibly from an existing Working Group, indicates that a major section of the Division's activities require a coordinating body for a longer period (a decade or more), the creation of a new Commission may be in order.

39.b. Whenever the Organizing Committee is satisfied that the creation of a new Working Group or Commission is well motivated, it may take immediate action as specified in Bye-Law $\S 21$ or Bye-Law $\S 23$. In any case, the Organizing Committee submits its complete proposal for the continuation, discontinuation, or merger of its Commissions and Working Groups to the General Secretary at least three months before the next General Assembly.

39.c. The President and Organizing Committee maintain frequent contacts with the other IAU Divisions to ensure that any newly emerging or interdisciplinary matters are addressed appropriately and effectively.

\section{TERMS OF REFERENCE FOR COMMISSIONS}

The role of the Commissions is to organize the work of the Union in specialized subsets of the fields of their parent Division(s), when the corresponding activity is judged to be of considerable significance over times of a decade or more. Thus, new Commissions may be created when fields emerge that are clearly in sustained long-term development and where the Union may play a significant role in promoting this development at the international level. Similarly, Commissions may be discontinued when their work can be accomplished effectively by the parent Division. In keeping with the many-sided activities of the Union, Commissions may have purely scientific as well as more organizational and/or interdisciplinary fields. They will normally belong and report to one of the IAU Divisions, but may be common to two or more Divisions. The following rules apply if a Division has more than one Commission.

40. The activities of a Commission are directed by an Organizing Committee of 4-8 members of the Commission, headed by a Commission President and Vice-President ( $c f$. Bye-Laws $§ 22$ ). A member of the Organizing Committee normally serves a maximum of two terms, unless elected Vice-President of the Commission in her/his second term. Presidents may serve for only one term. All members of the Organizing Committee are expected to be active in this task, and are to be consulted on all significant actions of the Commission. The Organizing Committee appoints a Commission Secretary who maintains the records of the membership and activities of the Commission in co-operation with the Division Secretary and the IAU Secretariat. Contact information for the members of the Organizing Committee shall be maintained at the Commission web site.

41. Individual Members of the Union, who are active in the field of the Commission and wish to contribute to its progress, are admitted as members of the Commission by the 
Organizing Committee. Interested Members should contact the Commission Secretary, who will bring the request before the Organizing Committee for decision. Members may resign from the Commission by notifying the Commission Secretary. Before each General Assembly, the Organizing Committee may also decide to terminate the Commission membership of persons who have not been active in the work of the Commission; the individuals concerned shall be informed of such planned action before it is put into effect. The Commission Secretary will report all changes in the Commission membership to the Division Secretary and the IAU Secretariat.

42. At least six months before a General Assembly, the Organizing Committee submits to the membership of the Commission a list of candidates for President, Vice-President (for which there should be the names of two persons willing to serve), and the Organizing Committee for the next triennium. The Organizing Committee requests nominations from the membership in preparing this list, and accepts additional nominations within a month after its submission to the membership. The Vice-President is normally nominated to succeed the President. The outgoing President participates in the deliberations of the new Organizing Committee in an advisory capacity. If more names are proposed than available elective positions, the outgoing Organizing Committee devises the procedure by which the requisite number of candidates is elected by the membership. The resulting list is submitted to the Organizing Committee of the parent Division(s) for approval before the end of the General Assembly. Members of the Organizing Committee normally serve a maximum of two terms, unless elected Vice-President of the Commission. Presidents may serve for only one term.

43. At least six months before each General Assembly, the Organizing Committee shall submit to the parent Division(s) a report on its activities during the past triennium, with its recommendation as to whether the Commission should be continued for another three years, or merged with one or more other Commissions, or discontinued. If a continuation is proposed, a plan for the activities of the next triennium should be presented, including those of any Working Groups which the Commission proposes to maintain during that period.

44. The Organizing Committee decides its own rules for the conduct of its business by physical meetings or (electronic) correspondence. Such rules require approval by the Organizing Committee of the parent Division(s). 